\title{
Adenine-induced hyperphosphatemia in a murine model of renal insufficiency
}

\author{
Elizabeth A Bobeck ${ }^{1}$, Michelle L Piccione ${ }^{2}$, JeffW Bishop ${ }^{2}$, Tyler G Fulmer ${ }^{2}$, Denise J Schwahn ${ }^{3}$, Christian Helvig ${ }^{4}$, Martin Petkovich ${ }^{4,5}$ and $^{2}$ \\ Mark E Cook ${ }^{2 *}$
}

${ }^{1}$ Animal Science Department, Iowa State University, Ames, Iowa, USA

${ }^{2}$ Animal Sciences Department, University of Wisconsin-Madison, Madison, Wisconsin, USA

${ }^{3}$ Research Animal Resources Center, University of Wisconsin-Madison, Madison, Wisconsin, USA

${ }^{4}$ Cytochroma Inc., Markham, Ontario, Canada

${ }^{5}$ Department of Biomedical and Molecular Sciences and Cancer Research Institute, Queen's University, Kingston, Ontario, Canada

\begin{abstract}
Hyperphosphatemia in chronic kidney disease (CKD) patients is a risk factor for cardiovascular events, progressive kidney failure, and mortality. Improved therapeutic interventions to control hyperphosphatemia depend greatly on robust animal models that recapitulate the CKD disease process. Murine-based models of CKD as compared to rat models present significant advantages due to available genetic knockout lines that permit mechanistic dissection of $\mathrm{CKD}$ etiologies. The rat adenine model of renal failure has been extensively studied, and studies are now emerging describing adenine-induced renal failure in murine models. However, these newly developed murine models have not fully described the responses to calcitriol and phosphate binders, and the reported effects of adenine on serum phosphate is often lacking in murine models. Therefore, the objectives of this study were: 1) To induce hyperphosphatemia in mice using adenine with minimal mortality, and 2) Report the influence of calcitriol and phosphate binders on the disease process through measurement of serum phosphate and histology. In one approach, C57BL/6 male mice gavaged with 4 or $6 \mathrm{mg}$ adenine/day, as compared to $0 \mathrm{mg}$ adenine/day developed hyperphosphatemia, with low mortality. In a second approach, calcitriol exacerbated adenine-induced increases in serum phosphate at day 7 of adenine administration ( $<<0.05)$. Notably, adenine treated mice had 4 -fold increased stomach weights vs. non-adenine treated mice $(\mathrm{p}<0.0001)$. The addition of a phosphate binder (experiment 3 , sevelamer hydrochloride) was ineffective at preventing an adenine-induced increase in blood phosphate, a finding that likely resulted from adenine's inhibition of gastric emptying. We report the successful use of adenine to induce hyperphosphatemia, that the hyperphosphatemic status is exacerbated by calcitriol, and a limitation of the model for studying oral therapies for hyperphosphatemia.
\end{abstract}

Abbreviations: FGF23: Fibroblast growth factor-23; CKD: Chronic kidney disease

\section{Introduction}

Hyperphosphatemia, a sequelae of chronic kidney disease (CKD), is responsible for decreased survival due to coronary artery disease, among other complications [1,2]. High blood phosphate levels in CKD patients are controlled by consuming diets low in inorganic phosphate, prescription of oral phosphate binders to bind dietary inorganic phosphate, and in the case of end stage failure, dialysis [3]. Improved methods to treat hyperphosphatemia are needed, as recent work capturing patient compliance reported that up to $45 \%$ of patients do not follow prescribed guidelines for use of oral phosphate binders [4,5]. Furthermore, concurrent active vitamin D supplementation prescribed due to a reduced ability of the kidney to convert vitamin precursors to active vitamin $\mathrm{D}$ further exacerbates phosphate absorption $[6,7]$. Previously, the rat models including the 5/6 nephrectomy and adenineinduced kidney insufficiency rat model have been extensively used for pre-clinical testing in the development of therapies for chronic kidney disease [8-10]. The rat adenine-induced kidney insufficiency model is a less invasive refinement over the $5 / 6$ nephrectomy surgical renal insufficiency model $[11,12]$, and was found useful in the development of sevelamer hydrochloride $(\mathrm{Sev} \mathrm{HCl})$ as an oral therapy for treatment of hyperphosphatemia [10]. Rats fed $0.75 \%$ dietary adenine for two weeks developed increased blood phosphate, FGF23, and blood urea nitrogen due to renal insufficiency, appearing sufficient to model human CKD $[8,9,11]$.

Only recently have murine models of CKD employed the use of adenine; a desirable extension of the rat model due to ease of genetic manipulation and conservation of testable compounds [2,1316]. Male C57BL/6 mice supplemented with $0.25 \%$ adenine had an accumulation of collagen and 2,8-dihydroxyadenine in renal tubules and an accompanying macrophage infiltrate [13]. Adenine-induced histological changes and select blood parameters in male C57BL/6 mice fed $0.75 \%$ adenine has also been described [14], and reported that $0.75 \%$ adenine was lethal by day 6 . Neither report evaluated the effects on blood phosphate status, a hallmark of human CKD. In a separate report, authors found that C57BL/6J mice fed $2 \%$ adenine in a casein-based diet had inconsistently increased serum phosphate over a d10-60 exposure period [15]. In a preliminary study in our laboratory, C57BL/6 male mice fed $0.25 \%$ or higher adenine showed outright food

Correspondence to: Mark E Cook, Animal Science Department, 1675 Observatory Drive, University of Wisconsin, Madison, WI, 53706, USA, Fax: 6082625157; Tel: 6082627747; E-mail: mcook@wisc.edu

Key words: hyperphosphatemia, renal insufficiency, chronic kidney disease, adenine

Received: May 28, 2017; Accepted: June 16, 2017; Published: June 19, 2017 
refusal within 3 days ( $3 \mathrm{~g} /$ day to $<1 \mathrm{~g} /$ day, unpublished data). Previous reports using $0.20 \%$ dietary adenine did not report anorexia but did show significant weight loss by day 10 of feeding adenine compared to control mice [15]. Exposure to adenine through food may have secondary anorexia effects through food refusal and may confound the examination of diet-based therapies, hence gavage was selected to ensure a daily dose of adenine regardless of feed intake.

Therefore, the objectives of this study were to: 1) Find a gavage dose of adenine that induced hyperphosphatemia without causing mortality; 2) Test the influence of calcitriol (a common active vitamin D therapy for CKD patients, and also known to increase phosphate absorption) in the mouse adenine model; and 3) Determine if sevelamer $\mathrm{HCl}$, a phosphate binder, prevents hyperphosphatemia in the mouse adenine model. Here, we report successful induction of hyperphosphatemia that was exacerbated by calcitriol supplementation. We also found that adenine interferes with gastric emptying; a limitation of this model in the study of oral therapies for preventing hyperphosphatemia.

\section{Materials and methods}

\section{Experiment 1}

All animal experimental procedures were approved by the University of Wisconsin-Madison College of Agricultural and Life Sciences Animal Care and Use Committee. Animals were housed in a facility with accreditation from AAALAC for the duration of the experiment. Adult male C57BL/6 7-8 weeks of age with littermate identity (Harlan Teklad, Madison, WI, $\mathrm{n}=36,12$ per treatment) were housed 3 per shoebox cage, as littermates, with a $12 \mathrm{~h}$ light/dark cycle. Mice were allowed free access to distilled water and a semi-purified sucrose/casein based diet (TD.10050, Harlan-Teklad, Madison, WI) formulated based on the AIN-76A diet (TD.94060, Harlan-Teklad) during a 7-day acclimatization period. This diet contained $6.85 \mathrm{~g}$ calcium $/ \mathrm{kg}$ diet and $5.61 \mathrm{~g}$ phosphate $/ \mathrm{kg}$ diet, with a calcium:phosphate ratio of 1.22 . Following acclimatization, 12 mice ( 4 cages of 3 mice) were assigned to each of the following gavage treatments where gavage was accomplished once daily for 14 days using an 18-gauge curved feeding

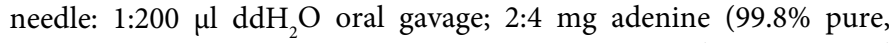

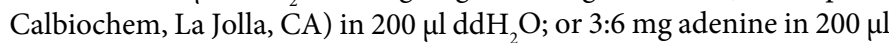
$\mathrm{ddH}_{2} \mathrm{O}$. As mice were expected to lose weight and body condition due to adenine treatment during induction of renal insufficiency, mice were removed from the experiment if they were observed to not eat or drink, or when body weight loss was $>40 \%$. Mice were weighed weekly and then bled under light isoflurane anesthesia using the axillary bleeding method at day 7 or 14 of the experimental gavaging period (6 mice were euthanized per time point). Euthanasia after bleeding under anesthesia was performed by cervical dislocation. Blood was collected into $400 \mu \mathrm{l}$ serum separator tubes (BD Medical, Franklin Lakes, NJ) and serum was separated and stored at $-80^{\circ} \mathrm{C}$ until phosphate, urea, and FGF23 were analyzed. The right kidney of each mouse was weighed separately for determination of kidney weight as a percentage of bodyweight.

\section{Serum analysis}

To determine serum phosphate, samples were analyzed in a 96-well Nunc Immunosorp flat-bottomed plate (Fisher Scientific, Rockford, Il) using the Pointe Scientific inorganic phosphorus reagent set (Canton, MI, P7516) and inorganic phosphorus standard (P7516-STD). Samples were loaded onto 2 duplicate plates; one for phosphorus reagent and the second was blanked using saline (control for each sample). Plates were read using a SpectraMax190 Plate reader (Molecular Devices, Sunnyvale, CA) with the SoftMax Pro 4.7.1 analysis program (Molecular
Devices, Sunnyvale, CA). Blanked values (phosphorus reagent-blank) were used to calculate final OD's to reduce overestimation of serum phosphate in the event of red blood cell lysis. Hence, the presence of lysis was indicated in results in Experiment 1.

Urea was analyzed in a 96-well plate using mouse serum and BioAssay Systems Quantichrom Urea Assay Kit according to manufacturer's instructions (DIUR-500, Hayward, CA). Remaining samples were analyzed using the Mouse FGF23 C-terminal ELISA kit (Immutopics International, San Clemente, CA) according to manufacturer directions. Control samples (no adenine) were not diluted for the FGF23 analysis; however, serum from adenine-treated animals was diluted 1:10 using C-term sample diluent (Immutopics International, San Clemente, CA) in order to assure samples were within the standard curve.

\section{Experiment 2}

Adult male C57BL/6 7-8 weeks of age with littermate identity (Harlan Teklad, $\mathrm{n}=72,18$ per treatment) were housed 3 per cage with a $12 \mathrm{~h}$ light/dark cycle and fed a semi-purified sucrose/casein-based diet based on AIN76-A (Harlan Teklad TD.110109). Following a 7-day acclimatization period, mice were assigned to one of 4 daily gavage treatments in order to determine the interaction of calcitriol (active Vitamin D) and renal failure, and resulting phosphate status: 1) 200 $\mathrm{c} \mu \mathrm{l}$ corn oil; 2) $200 \mathrm{c} \mu \mathrm{l}$ corn oil supplying $0.5 \mathrm{ug} / \mathrm{kg}$ body weight/day calcitriol (Enzo Life Sciences, Farmingdale, NY); 3) $200 \mu \mathrm{l}$ corn oil containing a suspension of $4 \mathrm{mg}$ adenine; 4) $200 \mu \mathrm{l}$ corn oil supplying $0.5 \mathrm{ug} / \mathrm{kg}$ bodyweight/day calcitriol plus $4 \mathrm{mg}$ adenine. Corn oil was used as a vehicle to accommodate calcitriol. Adenine dose $(4 \mathrm{mg} /$ day) was selected based on results from experiment 1 , which was the lowest dose of adenine that led to kidney dysfunction as measured by increased kidney weight, plasma urea, FGF23, and serum phosphate. Animals were gavaged for 14 days, weighed weekly, monitored, and bled as described in experiment 1 . Additionally, stomachs were collected, weighed, and expressed as percentage of bodyweight.

\section{Experiment 3}

Adult male C57BL/6 7-8 weeks of age with littermate identity (Harlan Teklad, $\mathrm{n}=48,12$ per treatment) were housed 3 per cage with a $12 \mathrm{~h}$ light/dark cycle. Mice were fed the diet as described in experiment 1 with or without a phosphate binder (1\% sevelamer HCl, Genzyme Corporation, Cambridge, MA; replacing a cellulose filler in the diet) and with or without daily adenine gavage $(0$ or $4 \mathrm{mg}$ /day in $200 \mu \mathrm{l}$ $\mathrm{ddH}_{2} \mathrm{O}$, as described above) to provide the following treatment groups; 1) Control diet with $0 \mathrm{mg}$ adenine gavage; 2) $1 \%$ dietary sevelamer $\mathrm{HCl}$ with $0 \mathrm{mg}$ adenine gavage; 3 ) Control diet with $4 \mathrm{mg}$ adenine gavage; or 4) $1 \%$ dietary sevelamer $\mathrm{HCl}$ with $4 \mathrm{mg}$ adenine gavage. Concentration of sevelamer was based on previous experiments in chick diets where $1 \%$ was successful in reducing plasma phosphate and bone ash [17], as well as the calculation that $1 \mathrm{~g}$ sevelamer can bind $0.45 \mathrm{~g}$ phosphate, hence $1 \%$ sevelamer could bind up to $80 \%$ of the phosphate in the mouse diet (which contains $0.56 \%$ phosphate [18]). The remaining $0.13 \%$ phosphate in the diet would leave the mice severely deficient. Diets were fed for 2 weeks and mice were bled, organs were collected, and serum was analyzed as described above.

\section{Kidney histology}

Upon sacrifice, kidneys were weighed and then transferred into $10 \%$ buffered formalin (Fisher Scientific, Waltham, MA) for 24-hour fixation at room temperature. Individual kidneys were embedded in 
paraffin, sectioned, and stained with hematoxylin and eosin (H\&E) before analysis by a board licensed veterinary pathologist (Author: DJS). Kidneys selected for photos were representative samples of 7and 14-day controls, 7- and 14-day with $4 \mathrm{mg}$ adenine gavage, 7 - and 14-day with $6 \mathrm{mg}$ adenine gavage, and 7-and 14-day $4 \mathrm{mg}$ gavage with calcitriol supplementation. Photos were taken at 200x on a Nikon Eclipse 50i Microscope (Melville, NY).

\section{Statistical analyses}

Data were analyzed using a one-way ANOVA for experiment 1 , and a two-way ANOVA with a $2 \times 2$ factorial arrangement of treatments in experiments 2 and 3 (experiment 2: with or without adenine and/ or active D (calcitriol), experiment 3: with or without adenine and/or sevelamer $\mathrm{HCl}$ ) (SAS Institute Inc., Cary, NC). Data in experiment 2 were analyzed for main effects of adenine, VitD (calcitriol), and the adenine X VitD interaction. Data in experiment 3 were analyzed for adenine, sevelamer $\mathrm{HCl}$, and the adenine $\mathrm{X}$ sevelamer $\mathrm{HCl}$ interaction. Post-ANOVA analyses comparisons of mean treatment differences were conducted even if the interactions were not significant $(p>0.05)$ using least squared differences such that significant effects could be easily discerned. The $\mathrm{p}$ values for main effects and interactions were provided for discernment regarding the least square differences. Data were expressed as mean and the overall standard error of the mean for each variable was provided.

\section{Results}

\section{Experiment 1}

The goal of this experiment was to identify a minimum level of gavaged adenine that induced hyperphosphatemia but did not increase mortality. In a preliminary trial (not shown), mice were gavaged with 0 , 1 , or $3 \mathrm{mg}$ adenine per day. After two weeks, average serum phosphate of the three groups were $7.0,6.9$, and $7.6 \mathrm{mg} / \mathrm{dL}$, respectively, hence higher doses of adenine ( $>3 \mathrm{mg} /$ day) appeared necessary to effectively induce hyperphosphatemia. In experiment 1 , gavaging $6 \mathrm{mg}$ adenine per day for 7 days significantly increased serum phosphate by 2.1 fold compared to $0 \mathrm{mg}$ control $(\mathrm{p}<0.01)$; at 14 days, gavaging 4 or 6 $\mathrm{mg}$ adenine per day significantly increased plasma phosphate above a vehicle gavaged control ( $\mathrm{p}<0.01$, Table 1$)$. Gavaging adenine decreased weight at both 7 and 14 days versus vehicle control $(\mathrm{p}<0.001)$, but mortality remained minimal with only 1 mouse in the $4 \mathrm{mg}$ and 2 mice in the $6 \mathrm{mg}$ groups requiring euthanasia before reaching their scheduled endpoint (day 7 or 14).

At day 7 and 14 days of treatment, 4 and $6 \mathrm{mg}$ adenine/day increased serum FGF-23 ( $>193$-fold, $\mathrm{p}<0.001$ ), urea (4-fold, $\mathrm{p}<0.0001$ ), and relative kidney weights $(1.5$-fold, $\mathrm{p}<0.0001)$. Adenine gavaged mice had reduced body weight $(13 \%$ to $25 \%, \mathrm{p}<0.001)$ when compared to mice not receiving adenine. Increase in adenine gavage from 4 to 6 $\mathrm{mg}$ /day did not impact variables measured except for FGF-23 at day 7 , where $6 \mathrm{mg}$ treated mice had an additional increase in serum FGF-23 compared to $4 \mathrm{mg}$ treated mice.

\section{Experiment 2}

Supplemental calcitriol (active vitamin D) is known to increase phosphate absorption [6,7,19]. The goal of experiment 2 was to determine the interaction of active vitamin $\mathrm{D}$ and adenine on phosphate metabolism during renal dysfunction (Table 2). For all variables measured, the addition of adenine (main effect: adenine) significantly increased serum phosphate, FGF23, urea, stomach and kidney weights, while decreasing body weight. While calcitriol had no impact on variables measured in the absence of adenine treatment (independent of interactions), calcitriol in the presence of adenine-induced renal failure altered biomarkers of abnormal phosphate homeostasis (Adenine X D Interaction). Calcitriol, when combined with adenine, increased serum phosphate (day 7 only, 1.2-fold, p <0.05), FGF23 ( $>2$-fold, $\mathrm{p}<0.0001$ ), relative kidney weight $(1.1$-fold, $\mathrm{p}<0.05)$ and reduced body weight $(\geq 8 \%, \mathrm{p}<0.01)$ compared to the adenine supplementation without calcitriol. During necropsy for determining kidney weights (Figure 1), it was observed that stomachs were enlarged; hence stomachs were collected and weighed (Figure 2). Apart from the enlargement (approximately 4 -fold) due to adenine treatment $(\mathrm{p}<0.0001)$, calcitriol had no effect on stomach tissue weights (emptied and weighed). Total mortality, including euthanasia according to protocol and before endpoints, was 0 in control mice, 1 in + vitamin D mice, 3 in + adenine mice, and 4 in + adenine + vitamin D mice.

\section{Experiment 3}

In experiment 3 , the effectiveness of the phosphate binder, sevelamer $\mathrm{HCl}$, to prevent adenine-induced hyperphosphatemia was investigated (Table 3). Sevelamer $\mathrm{HCl}$ was ineffective at preventing an adenine-induced increase in blood phosphate, urea, relative stomach weight and decreased body weight. On day 14, but not day 7, sevelamer reduced adenine induced increases in serum FGF23 (adenine $\mathrm{X}$ sevelamer, $\mathrm{p}=0.0017)$. Increases in kidney weight induced by adenine by day 14 , but not day 7 , was exacerbated by sevelamer treatment (adenine $\mathrm{X}$ sevelamer, $\mathrm{p}=0.04$ ). As observed in experiment 2 , adenine administration increased full and empty stomach weights by 3 and 1.4fold, respectively $(\mathrm{p}=0.0007)$ when compared to mice that received no supplemental adenine or sevelamer $\mathrm{HCl}$. The addition of sevelamer $\mathrm{HCl}$ to the adenine treatment increased full and empty stomach

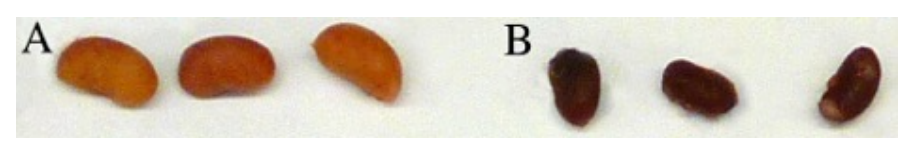

Figure 1. Excised kidneys of mice from experiment 2 at day 14 either gavaged with $4 \mathrm{mg}$ adenine/ day (A) or $0 \mathrm{mg}$ (vehicle) (B). Mice were orally gavaged 0 or $4 \mathrm{mg}$ adenine for 2 weeks and kidneys were excised for appearance and weight determination. The main effect of adenine on increasing kidney weight was significant at $\mathrm{p}<0.0001$. Note the lighter color of adenine treated mice (A)

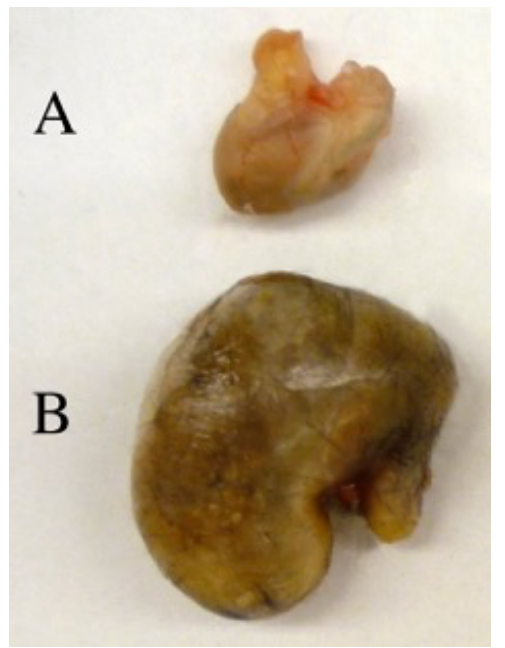

Figure 2. Excised full stomachs of mice from experiment 2 at 14 days either on control $+0 \mathrm{mg}$ (vehicle) (2A) or control $+4 \mathrm{mg}$ adenine/ day (2B). Mice were orally gavaged with 0 or $4 \mathrm{mg}$ adenine for 14 days. Stomachs of adenine-treated mice were observed to be larger during kidney excision; hence stomachs were collected and weighed during necropsy. The main effect of adenine on increasing stomach weight was significant at $p<0.0001$ 
Table 1. Experiment 1. Serum measurements (phosphate, FGF23, urea) and weight (kidney and body weight) parameters of mice at day 7 and day 14 of experimental trial. Mice ( $\mathrm{n}=12$ ) were gavaged with either 0 (control), 4, or $6 \mathrm{mg}$ adenine per day and half were euthanized at day 7 and the remainder at day 14 . Results are shown above as mean with pooled standard error of the mean. Differing superscript letters within columns denote significant differences between treatment groups $(\mathrm{p}<0.05)$.

\begin{tabular}{|c|c|c|c|c|c|c|c|c|c|c|}
\hline $\begin{array}{l}\text { Treatment } \\
\text { (mg/day) }\end{array}$ & Pi d7 (mg/dL) & $\begin{array}{c}\text { Pi d14 (mg/ } \\
\text { dL) }\end{array}$ & $\begin{array}{c}\text { FGF23 d7 (pg/ } \\
\text { ml) }\end{array}$ & $\begin{array}{c}\text { FGF23 d14 } \\
(\mathrm{pg} / \mathrm{ml})\end{array}$ & $\begin{array}{l}\text { Urea d7 (mg/ } \\
\text { dL) }\end{array}$ & $\begin{array}{l}\text { Urea d14 (mg/ } \\
\text { dL) }\end{array}$ & $\begin{array}{l}\text { Kidney d7 } \\
\text { (\%BW) }\end{array}$ & $\begin{array}{c}\text { Kidney d14 } \\
\text { (\%BW) }\end{array}$ & BW d7 (g) & BW d14 (g) \\
\hline Gavage 0 & $5.1^{\mathrm{b}}$ & $11.1^{* b}$ & $150^{c}$ & $45^{\mathrm{b}}$ & $90.4^{\mathrm{b}}$ & $72.9^{b}$ & $0.73^{b}$ & $0.89^{b}$ & $23.6^{\mathrm{a}}$ & $22.1^{\mathrm{b}}$ \\
\hline Gavage 4 & $9.0^{\mathrm{ab}}$ & $16.1^{\mathrm{a}}$ & $28897^{\mathrm{b}}$ & $13898^{\mathrm{a}}$ & $352.9^{\mathrm{a}}$ & $247.8^{\mathrm{a}}$ & $1.21^{\mathrm{a}}$ & $1.26^{\mathrm{a}}$ & $18.7^{\mathrm{b}}$ & $18.4^{\mathrm{c}}$ \\
\hline Gavage 6 & $10.8^{\mathrm{a}}$ & $15.9^{\mathrm{a}}$ & $33821^{a}$ & $11347^{\mathrm{a}}$ & $393.7^{\mathrm{a}}$ & $267.8^{\mathrm{a}}$ & $1.22^{\mathrm{a}}$ & $1.33^{\mathrm{a}}$ & $17.6^{\mathrm{b}}$ & $19.2^{\mathrm{c}}$ \\
\hline Pooled SE & 1.5 & 0.59 & 5824 & 2408 & 15.2 & 23.4 & 0.05 & 0.08 & 0.57 & 0.49 \\
\hline
\end{tabular}

*Lysis in $0 \mathrm{mg}$ / day gavage control group that caused artificially high serum phosphate results.

D: Day; Pi: Inorganic phosphate; FGF23: Ffibroblast growth factor 23; BW: Body weight

Table 2. Experiment 2. Serum, organ, and body weight results from mice gavaged 0 or $4 \mathrm{mg}$ adenine/day with or without calcitriol with mean $\pm \mathrm{SEM}$ at day 7 or 14 . Mice ( $\mathrm{n}=18 /$ group) were placed into one of 4 treatment groups arranged in a $2 \times 2$ factorial control diet with or without adenine $(0$ or $4 \mathrm{mg}$ adenine/ day), and with or without calcitriol (Vit $\mathrm{D}, 0.5 \mu \mathrm{g} / \mathrm{kg}$ bodyweight calcitriol per day) for 7 or 14 days. Kidney and stomach weights are shown as percent of bodyweight. Differing superscript letters denote significant difference between treatment group means within the same column $(\mathrm{p}<0.05)$. Main effects of VitD (calcitriol) and adenine, and the adenine X VitD interaction $\mathrm{p}$ values are shown

\begin{tabular}{|c|c|c|c|c|c|c|c|c|c|c|c|}
\hline Treatment & $\begin{array}{l}\text { Pi d7 (mg/ } \\
\text { dL) }\end{array}$ & $\begin{array}{c}\text { Pi d14 (mg/ } \\
\text { dL) }\end{array}$ & $\begin{array}{c}\text { FGF23 d7 } \\
(\mathrm{pg} / \mathrm{ml})\end{array}$ & $\begin{array}{c}\text { FGF23 d14 } \\
(\mathrm{pg} / \mathrm{ml})\end{array}$ & $\begin{array}{c}\text { Urea d14 } \\
\text { (mg/dL) }\end{array}$ & $\begin{array}{c}\text { Kidney d7 } \\
\text { (\%BW) }\end{array}$ & $\begin{array}{c}\text { Kidney d14 } \\
\text { (\%BW) }\end{array}$ & BW d7 (g) & BW d14 (g) & $\begin{array}{c}\text { Full } \\
\text { Stomach d7 } \\
(\% \mathrm{BW})\end{array}$ & $\begin{array}{c}\text { Full } \\
\text { Stomach } \\
\text { d14 }(\% \mathrm{BW})\end{array}$ \\
\hline Vehicle Control & $6.8^{\mathrm{c}}$ & $5.8^{\mathrm{b}}$ & $229^{c}$ & $336^{\mathrm{c}}$ & $24.0^{\mathrm{b}}$ & $0.76^{\mathrm{b}}$ & $0.78^{c}$ & $24.5^{\mathrm{a}}$ & $26.0^{\mathrm{a}}$ & $0.69^{\mathrm{b}}$ & $0.63^{\mathrm{b}}$ \\
\hline VitD & $5.9^{\mathrm{c}}$ & $5.4^{\mathrm{b}}$ & $904^{c}$ & $1457^{\mathrm{c}}$ & $27.4^{\mathrm{b}}$ & $0.78^{\mathrm{b}}$ & $0.72^{\mathrm{c}}$ & $24.8^{\mathrm{a}}$ & $25.0^{\mathrm{a}}$ & $0.65^{\mathrm{b}}$ & $0.61^{\mathrm{b}}$ \\
\hline Control+Adenine & $10.5^{\mathrm{b}}$ & $12.5^{\mathrm{a}}$ & $17814^{\mathrm{b}}$ & $31795^{b}$ & $166.4^{\mathrm{a}}$ & $1.12^{\mathrm{a}}$ & $1.42^{\mathrm{b}}$ & $19.1^{\mathrm{b}}$ & $21.1^{\mathrm{b}}$ & $2.74^{\mathrm{a}}$ & $2.92^{\mathrm{a}}$ \\
\hline Control+Adenine+VitD & $12.9^{\mathrm{a}}$ & $11.5^{\mathrm{a}}$ & $66535^{\mathrm{a}}$ & $72270^{\mathrm{a}}$ & $148.2^{\mathrm{a}}$ & $1.16^{\mathrm{a}}$ & $1.59^{\mathrm{a}}$ & $17.5^{\mathrm{c}}$ & $16.3^{\mathrm{c}}$ & $2.85^{\mathrm{a}}$ & $2.82^{\mathrm{a}}$ \\
\hline Pooled SE & 0.63 & 0.55 & 3378 & 1929 & 5.58 & 0.035 & 0.056 & 0.40 & 0.57 & 0.22 & 0.34 \\
\hline Main Adenine & $<0.0001$ & $<0.0001$ & $<0.0001$ & $<0.0001$ & $<0.0001$ & $<0.0001$ & $<0.0001$ & $<0.0001$ & $<0.0001$ & $<0.0001$ & $<0.0001$ \\
\hline Main VitD & 0.253 & 0.216 & $<0.0001$ & $<0.0001$ & 0.204 & 0.462 & 0.29 & 0.103 & $<0.0001$ & 0.892 & 0.862 \\
\hline Adenine $x$ VitD & 0.252 & 0.520 & $<0.0001$ & $<0.0001$ & 0.069 & 0.80 & 0.047 & $<0.001$ & 0.002 & 0.752 & 0.898 \\
\hline
\end{tabular}

VitD: Calcitriol; d: Day; FGF23: Fibroblast growth factor 23; BW: Bodyweight.

Post-ANOVA comparisons were made even if interactions were not significant in order to highlight main effects.

Table 3. Experiment 3. Serum, organ, and weight data (mean \pm SEM) from mice ( $n=12 /$ group) placed into one of 4 treatment groups arranged in a $2 \times 2$ factorial $( \pm$ adenine and $\pm 1 \%$ dietary sevelamer $\mathrm{HCl}$ ). Mice were gavaged with 0 or $4 \mathrm{mg}$ adenine/ day and received 0 or $1 \%$ dietary sevelamer $\mathrm{HCl}$ for 7 or 14 days. Kidney, full stomach, and empty stomach weights are shown as percent of bodyweight. Main effects of adenine and sevelamer, and the adenine X sevelamer interaction p values are shown. Differing superscript letters denote significant difference between treatment groups in the same column $(\mathrm{p}<0.05)$

\begin{tabular}{|c|c|c|c|c|c|c|c|c|c|c|c|c|}
\hline Treatment & $\begin{array}{c}\text { Pi d7 (mg/ } \\
\text { dL) }\end{array}$ & $\begin{array}{c}\text { Pi d14 (mg/ } \\
\text { dL) }\end{array}$ & $\begin{array}{c}\text { FGF23 d7 } \\
(\mathrm{pg} / \mathrm{ml})\end{array}$ & $\begin{array}{c}\text { FGF23 d14 } \\
(\mathrm{pg} / \mathrm{ml})\end{array}$ & $\begin{array}{l}\text { Urea d14 } \\
(\mathrm{mg} / \mathrm{dL})\end{array}$ & $\begin{array}{c}\text { Kidney d7 } \\
(\% \mathrm{BW})\end{array}$ & $\begin{array}{c}\text { Kidney d14 } \\
\text { (\%BW) }\end{array}$ & BW d7 (g) & BW d14 (g) & $\begin{array}{c}\text { Full } \\
\text { Stomach } \\
\text { d7 (\%BW) }\end{array}$ & $\begin{array}{c}\text { Full } \\
\text { Stomach } \\
\text { d14 } \\
(\% \mathrm{BW})\end{array}$ & $\begin{array}{c}\text { Empty } \\
\text { Stomach } \\
\text { d14 } \\
(\% \mathrm{BW})\end{array}$ \\
\hline Control & $8.4^{\mathrm{ab}}$ & $7.1^{\mathrm{b}}$ & $180^{\mathrm{b}}$ & $302^{\mathrm{b}}$ & $69.8^{\mathrm{c}}$ & $0.79^{\mathrm{b}}$ & $0.75^{\mathrm{c}}$ & $23.4^{\mathrm{a}}$ & $24.7^{\mathrm{a}}$ & $0.82^{\mathrm{c}}$ & $0.82^{\mathrm{c}}$ & $0.39^{\mathrm{c}}$ \\
\hline Sev & $6.3^{b}$ & $8.1^{\mathrm{b}}$ & $175^{b}$ & $234^{b}$ & $62.7^{\mathrm{c}}$ & $0.78^{b}$ & $0.79^{\mathrm{c}}$ & $24.5^{\mathrm{a}}$ & $25.4^{\mathrm{a}}$ & $0.82^{\mathrm{c}}$ & $0.82^{\mathrm{c}}$ & $0.54^{\mathrm{b}}$ \\
\hline Control+Adenine & $9.3^{\mathrm{ab}}$ & $10.3^{\mathrm{b}}$ & $21679^{a}$ & $24775^{\mathrm{a}}$ & $274.7^{\mathrm{a}}$ & $1.4^{\mathrm{a}}$ & $1.4^{\mathrm{b}}$ & $19.9^{\mathrm{b}}$ & $19.6^{\mathrm{b}}$ & $2.50^{\mathrm{b}}$ & $3.10^{\mathrm{b}}$ & $0.57^{\mathrm{b}}$ \\
\hline Sev+Adenine & $10.1^{\mathrm{a}}$ & $10.7^{\mathrm{a}}$ & $15419^{\mathrm{a}}$ & $5625^{\mathrm{b}}$ & $256.0^{\mathrm{b}}$ & $1.4^{\mathrm{a}}$ & $1.7^{\mathrm{a}}$ & $18.8^{\mathrm{b}}$ & $20.2^{\mathrm{b}}$ & $3.50^{\mathrm{a}}$ & $3.70^{\mathrm{a}}$ & $0.71^{\mathrm{a}}$ \\
\hline Pooled SE & 1.06 & 0.67 & 3432 & 2593 & 6.2 & 0.04 & 0.05 & 0.64 & 0.45 & 0.22 & 0.19 & 0.05 \\
\hline Main Adenine & 0.042 & 0.0004 & $<0.0001$ & $<0.0001$ & $<0.0001$ & $<0.0001$ & $<0.0001$ & $<0.0001$ & $<0.0001$ & $<0.0001$ & $<0.0001$ & $<0.001$ \\
\hline Main Sev & 0.552 & 0.327 & 0.374 & 0.002 & 0.053 & 0.890 & 0.008 & 0.976 & 0.313 & 0.062 & 0.114 & $<0.001$ \\
\hline Adenine $x$ Sev & 0.176 & 0.666 & 0.375 & 0.002 & 0.353 & 0.97 & 0.040 & 0.089 & 0.942 & 0.062 & 0.229 & 0.924 \\
\hline
\end{tabular}

d: Day, FGF23: Fibroblast growth factor 23, Sev: Sevelamer HCl, BW: Bodyweight.

Post-ANOVA comparisons were made even if interactions were not significant in order to highlight main effects.

weights, when compared to mice only receiving adenine treatment. All mice in non-adenine treated groups survived until scheduled endpoint. One mouse was euthanized in the adenine treatment group, and two in the adenine+sevelamer $\mathrm{HCl}$ treatment group.

\section{Histology}

Figures $3 \mathrm{~A}$ and $3 \mathrm{~B}$ show kidney sections of control mice at 7 and 14 days with normal renal cortexes. At 7 and 14 days for mice receiving the $4 \mathrm{mg}$ or $6 \mathrm{mg}$ adenine gavage, kidney tubules show distention with dilated, degenerating epithelium and material that may represent crystallizing adenine metabolites consistent with previous adenineinduced kidney injury models [20] (Figures 3C-3F). An increase in interstitial fibroblasts is seen in $6 \mathrm{mg}$ gavage at 14 days (Figure $3 \mathrm{~F}$ ). Kidneys of mice gavaged for 7 or 14 days with $4 \mathrm{mg}$ adenine + calcitriol supplementation had similar kidney injuries as mice gavaged with $4 \mathrm{mg}$ adenine for 7 or 14 days without additional calcitriol supplementation
(Figures 3G-3H). The effect of vitamin D toxicoses (corticomedullary junction mineralization) from 14 day calcitriol supplementation is seen in Figure $3 \mathrm{H}$. In all cases of adenine gavage, crystallization is more evident at 14 days than at 7 days.

\section{Discussion}

Rats have been the model of choice for studying adenineinduced hyperphosphatemia, and the advantages of murine-based adenine models have been recently realized and reported by several investigators $[2,15,16,21]$. A reliable model of chemically-induced hyperphosphatemia in mice is useful since mice require less test compound and knockouts are widely available for studying basic mechanisms involving hyperphosphatemia. It has been demonstrated that mice have a relatively higher sensitivity to adenine-induced toxicity than rats. Rats tolerate dietary levels of adenine at $0.75 \%$ for prolonged periods ( 8 weeks or more) $[9,11,19,22]$, whereas mice show 


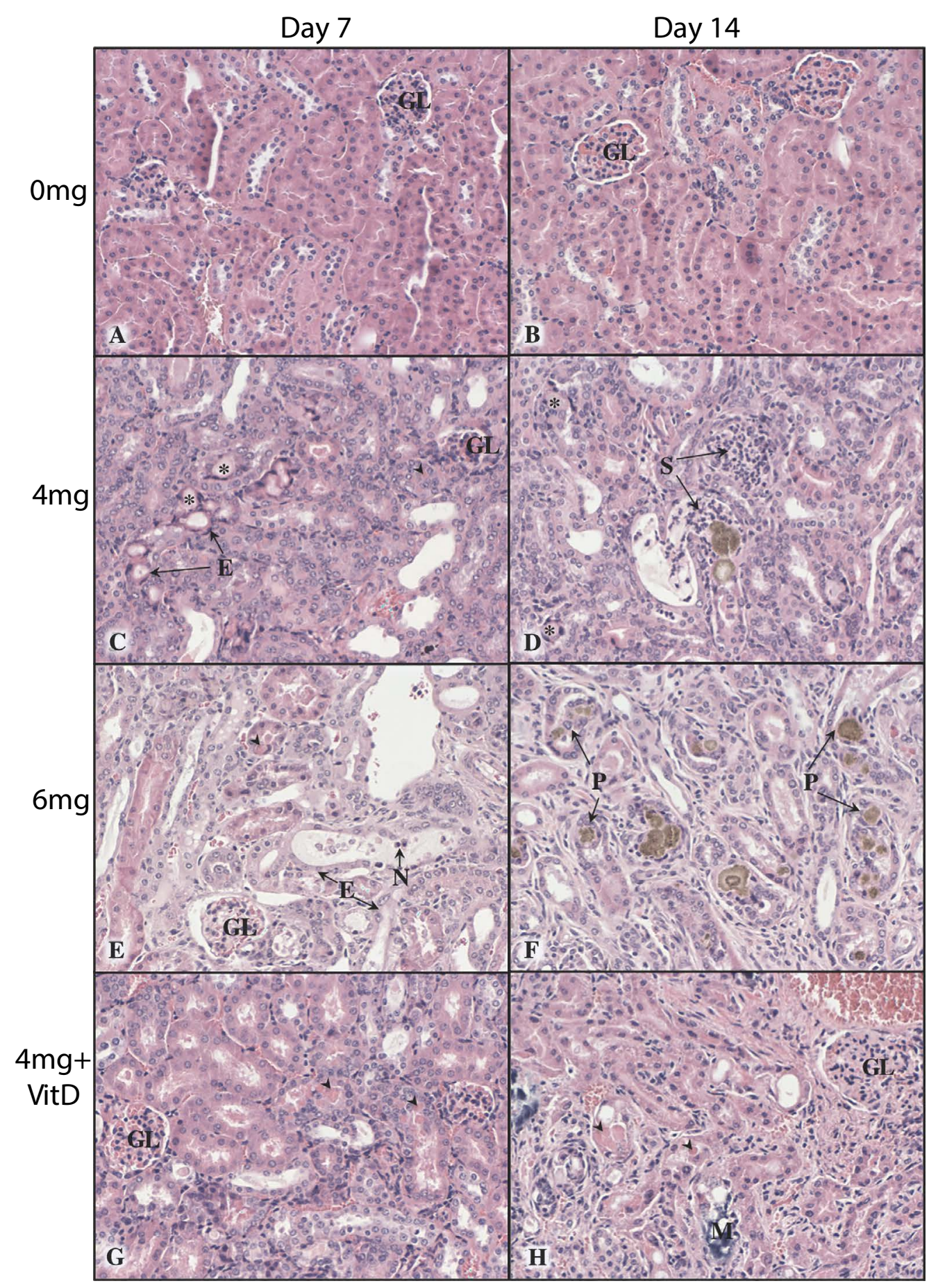

Figure 3. Histology of sliced/ H\&E stained kidneys from selected groups in murine adenine-induced kidney insufficiency studies. In panels A-F,C57Bl/6 mice were treated with either 0 , 4 , or $6 \mathrm{mg}$ adenine/ day (rows) in 200ul ddH2O for 7 or 14 days (columns). In panels $\mathrm{G}$ and $\mathrm{H}$, mice were gavaged with $4 \mathrm{mg}$ adenine/ day + active vitamin $\mathrm{D}$ in corn oil ( 7 or 14 days), and the $0 \mathrm{mg} /$ day adenine corn oil control were reflective of panels A and B. Kidneys were fixed in formalin for 24 hours at room temperature and then transferred to PBS until sectioning and staining with H\&E.A: 7 day control, non-adenine treated control mouse. Normal renal cortex. GL, glomerulus. 200X; B: 14 day control, non-adenine treated control mouse. Normal renal cortex. 200X; C: 7 day $4 \mathrm{mg}$. Renal tubules are frequently distended. Some contain amorphous clear or pale brown crystals $(*)$ and are lined by attenuated, degenerating epithelium (E). Brightly eosinophilic intratubular material that may represent crystallizing adenine metabolites is present at low levels (arrowhead). 200X; D: 14 day $4 \mathrm{mg}$. Renal tubules often contain spiky brown crystals, presumed to be adenine metabolites, as they resemble the crystals seen in the Aprt knockout mouse [20]. The crystals occasionally induce epithelial necrosis and subsequent suppurative inflammation (S). Tubular epithelium is often attenuated and flattened (regeneration). Crystals in various stages of nucleation are noted $(*)$. 200X; E: 7 day $6 \mathrm{mg}$. Renal tubules are markedly degenerate and dilated; they are commonly lined by flattened, attenuated epithelium (E) and contain necrotic cellular debris (N) (degeneration). Eosinophilic material interpreted as crystallizing adenine metabolites is noted (arrowhead). 200X; F: 14 day $6 \mathrm{mg}$. Large numbers of spiky brown crystals (adenine metabolites) are noted within renal tubules. They appear to induce epithelial proliferation (P), thereby "coating" themselves in degenerate epithelium. Many tubules are lined by flattened, attenuated (regenerating) epithelium, and there is an increase in interstitial cells (fibroblasts). 200X; G: 7 day $4 \mathrm{mg}$ with Vitamin D. Renal tubules are commonly filled with brightly eosinophilic debris (arrowheads); this material is interpreted as crystallizing adenine metabolites. Tubular epithelium is occasionally flattened or irregular (degeneration). 200X; H: 14 day $4 \mathrm{mg}$ with Vitamin D. Large quantities of brightly eosinophilic intratubular material (arrowheads) interpreted as crystallizing adenine metabolites are noted; there is accompanying tubular degeneration. Tubules at the corticomedullary junction are undergoing mineralization $(\mathrm{M})$, as is consistent with Vitamin D toxicosis. There are increased interstitial fibroblasts and subsequent fibrosis. 200X 
$100 \%$ mortality by day 6 when fed $0.75 \%$ dietary adenine [14]. Renal dysfunction has been shown in mice when fed $0.25 \%$ of the diet for up to 28 days; however, when we attempted to study $0.25 \%$ adenine in the diet, we saw profound feed refusal (control=3 g/mouse $/$ day, $0.25 \%$ adenine $\leq 1 \mathrm{~g} /$ mouse/day; unpublished), which presents a problem for studying dietary intervention for the control of hyperphosphatemia. Studies that have investigated adenine-induced renal dysfunction have reported phosphate status in mice; however, serum phosphate was not significantly different from control phosphate at all time points selected post-induction of dietary adenine, likely due to alternating dietary adenine inclusion between 0.15 and $0.20 \%$ over a 60 day period [15]. Hence we sought to develop an adenine model that minimized weight loss possibly due to feed refusal, resulted in low or no mortality, effectively induced permanent changes in phosphate status, and did not confound feed intake with several dietary additives (i.e., adenine plus test compounds to alleviate renal dysfunction).

In preliminary gavage experiments, 8 or $9 \mathrm{mg}$ adenine/day was lethal, while adenine at 1 or $3 \mathrm{mg} /$ day failed to induce increases in blood phosphate within a 14-day period (unpublished). In the first dosing experiment shown in this paper, we found that altered phosphate status (e.g. increased serum phosphate and FGF23) could be induced in mice with a $4 \mathrm{mg}$ adenine/day gavage without substantial effects on bodyweight loss, and mortality. The increase in serum phosphate in mice receiving an adenine gavage was similar to what has been reported in studies using rats [8]. Increases in kidney weight and serum urea were consistent with renal dysfunction $[11,14]$. The marked increase in blood FGF23 has been previously reported during renal failure $[8,15,23]$. FGF23 is a bone-derived hormone responsible for the regulation of blood phosphate homeostasis and is responsible for increasing renal excretion of blood phosphate by down regulation of the renal sodium-dependent phosphate co-transporter $2 \mathrm{a}(\mathrm{NaPi} 2 \mathrm{a})$, a transporter responsible for the renal resorption of phosphate. FGF23 also increases degradation of 1, 25-dihydroxycholecalciferol (active vitamin $\mathrm{D}$ ) and thereby decreases phosphate absorption from the intestinal tract via the sodium-dependent phosphate co-transporter $2 \mathrm{~b}$ (NaPi2b) [7]. Hence, elevated levels of serum FGF23 is indicative of a mechanism to normalize blood phosphate homeostasis in animals with normal renal function.

In the second experiment, we attempted to show that the use of calcitriol $\left(1,25-(\mathrm{OH})_{2} \mathrm{D}_{3}\right)$ would exacerbate the hyperphosphatemic status of renal compromised mice. It is well known that calcitriol increases the transport of dietary phosphate in the intestine by increasing the number of sodium-dependent phosphate co-transporters on the brush border membrane [24]. Patients with CKD are often treated with active vitamin $\mathrm{D}$ analogs to maintain calcium homeostasis and control secondary hyperparathyroidism [25]; however, treatment of CKD patients with calcitriol has been shown to increase blood phosphate [6]. In the short experimental period shown in this paper, daily doses of calcitriol increased serum phosphate at day 7 but not day 14. Histology revealed that the mice were undergoing a state of vitamin D toxicosis (Figure $3 \mathrm{H}$ ). Elevated FGF23 in mice treated with calcitriol was likely successful in controlling blood phosphate levels at day 14 by increased renal excretion of phosphate and increased degradation of calcitriol, and thus decreased absorption of dietary phosphate [22]. The reduction in body weight and increased in relative kidney size as a result of supplementing adenine-treated mice with calcitriol further supports that phosphate metabolism was altered by treating mice with calcitriol during renal dysfunction. These findings suggest that the mouse adenine model, as described, could be useful in studying the adverse affects of calcitriol therapy on phosphate homeostasis.
The primary approach to manage hyperphosphatemia in the CKD patient is through oral administration of phosphate binders and dietary phosphate reduction $[3,26]$. Failure to control the hyperphosphatemic condition in CKD patients significantly increases the risk of cardiovascular disease [27]. Modifying the diet to reduce bioavailable phosphate has limited usefulness, but is likely even less effective when combined with calcitriol therapy. Calcitriol therapy may increase the bioavailablity of phytate phosphate by indirect actions of vitamin $\mathrm{D}$ $[28,29]$ and direct actions of intestinal alkaline phosphatase [30-32]. Hence, the most useful available therapies for the control of blood phosphate are oral supplements such as phosphate binders.

For an animal model of kidney disease to be useful in the study of oral therapies for the control of hyperphosphatemia, gut function should remain intact. During the gavage studies, it was noted that the stomachs were enlarged in mice treated with adenine. While it had been previously reported that CKD could alter gastrointestinal motility [33], there was no mention in the animal literature of enlarged stomachs $[8,13,14]$. The significant enlargement of the stomach caused by adenine supplementation suggested that adenine use in the mouse model might compromise oral administration of test therapies. Stomach enlargement was not the result of gavage techniques since control mice did not experience enlarged stomachs (Figure 2; Tables 2 and 3).

To determine if the enlarged stomachs associated with adenine treatment would impair the study of oral supplements to prevent hyperphosphatemia, we studied the interaction of adenine and sevelamer. Sevelamer $\mathrm{HCl}$ has been shown to be effective at treating adenine-induced hyperphosphatemia in rats $[8,10]$, and $5 / 6$ nephrectomy-induced hyperphosphatemia in mice [34] and rats [35]. We have recently demonstrated in chicks that sevelamer $\mathrm{HCl}$ was effective in preventing the absorption of phosphate liberated from the diet due to the treatment of calcitriol [17]. In this report, we found that while sevelamer $\mathrm{HCl}$ caused a modest reduction in serum FGF23 after 14 days of supplementation in adenine treated mice, sevelamer $\mathrm{HCl}$ was ineffective at preventing hyperphosphatemia in this model. Sevelamer was supplemented at $1 \%$ of the diet, and could potentially bind $0.45 \%$ of the $0.56 \%$ dietary phosphate. While sevelamer was not fed in excess, the remaining $0.13 \%$ phosphate in the diet would have left mice severely deficient had sevelamer bound maximal capacity of phosphate.

It is also likely that sevelamer's ineffectiveness in this model was due to the effect of adenine on gut emptying [36]. The nearly 4-fold increase in stomach weight due to adenine treatment appeared to be mostly accumulated food. When stomachs were emptied of their contents (contents were diet in appearance), the increase in size due to adenine use was largely lost. These results suggest that effectiveness of sevelamer $\mathrm{HCl}$ may have been limited by compromised movement through the stomach to reach and bind phosphate in the small intestine where phosphate is absorbed. To effectively complex phosphate, sevelamer must be in an environment where $\mathrm{pH}$ is greater than 5 (such as found in the small intestine); sevelamer is unable to bind phosphate in the stomach where the $\mathrm{pH}<4$ [37]. Future work should be conducted with an increased inclusion of sevelamer $(3 \%)$ in order to determine the contribution of sevelamer dose versus emptying effect on reducing hyperphosphatemia.

\section{Conclusion}

In conclusion, we have successfully refined a murine adenine model of renal dysfunction that can be useful for the study of hyperphosphatemia. The model is responsive to calcitriol as would be predicted, and histology shows that adenine metabolites are 
accumulating in kidney tissue and causing mechanical damage, inflammation, and reduced filtration. A limitation of the model would be the study of dietary modifications or oral supplements that are added to the food supply since the use of adenine in the mouse models appears to influence stomach emptying.

\section{Funding}

Research was supported through royalties received from the Wisconsin Alumni Research Foundation (WARF) and through a sponsored research agreement with Cytochroma, Inc.

\section{Acknowledgement}

The authors would like to thank Jordan Sand for aiding in sample collection, the UW Animal Care Staff (Terry Jobsis, Dawn Irish, and Angel Gutierrez-Velin) for animal care, and Joan Parrish for photo preparation.

\section{Declaration of interest}

The authors report no conflicts of interest. The authors alone are responsible for the content and writing of the paper.

\section{References}

1. Block GA, Klassen PS, Lazarus JM, Ofsthun N, Lowrie EG, et al. (2004) Mineral metabolism, mortality, and morbidity in maintenance hemodialysis. J Am Soc Nephrol 15: 2208-2218. [Crossref]

2. Kaludjerovic J, Komaba H, Sato T, Erben RG, Baron R, et al. (2017) Klotho expression in long bones regulates FGF23 production during renal failure. FASEB $J$ 31: 20502064. [Crossref]

3. Uribarri J (2007) Phosphorus homeostasis in normal health and in chronic kidney disease patients with special emphasis on dietary phosphorus intake. Seminars in Dial 20: 295-301. [Crossref]

4. Gonzalez-Parra E, Tunon J, Egido J, Ortiz A (2012) Phosphate: a stealthier killer than previously thought? Cardiovasc Path 21(5): 372-381. [Crossref]

5. Fissell RB, Karaboyas A, Bieber BA, Sen A, Li Y, et al. (2015) Phosphate binder pill burden, patient-reported non-adherence, and mineral bone disorder markers: Findings from the DOPPS. Mineral Bone Dis 20: 38-49. [Crossref]

6. Palmer SC, McGregor DO, Craig JC, Elder G, Macaskill P, et al. (2009) Vitamin D compounds for people with chronic kidney disease requiring dialysis. Cochrane Database Syst Rev. [Crossref]

7. Quarles LD (2012) Role of FGF23 in vitamin D and phosphate metabolism: implications in chronic kidney disease. Exp Cell Res 318: 1040-1048. [Crossref]

8. Nagano N, Miyata S, Abe M, Kobayashi N, Wakita S, et al. (2006) Effect of manipulating serum phosphorus with phosphate binder on circulating PTH and FGF23 in renal failure rats. Kidney Int 69: 531-537. [Crossref]

9. Tamagaki K, Yuan Q, Ohkawa H, Imazeki I, Moriguchi Y, et al. (2006) Severe hyperparathyroidism with bone abnormalities and metastatic calcification in rats with adenine-induced uraemia. Nephrol dial transplant 21: 651-659. [Crossref]

10. Katsumata K, Kusano K, Hirata M, Tsunemi K, Nagano N, et al. (2003) Sevelamer hydrochloride prevents ectopic calcification and renal osteodystrophy in chronic renal failure rats. Kidney Int 64: 441-450. [Crossref]

11. Okada H, Kaneko Y, Yawata T, Uyama H, Ozono S, et al. (1999) Reversibility of adenine-induced renal failure in rats. Japanese Soc Nephrol 3: 82-88.

12. Fleck C, Appenroth D, Jonas P, Koch M, Kundt G, et al. (2006) Suitability of 5/6 nephrectomy $(5 / 6 \mathrm{NX})$ for the induction of interstitial renal fibrosis in rats--influence of sex, strain, and surgical procedure. Exp Toxicol Pathol 57: 195-205. [Crossref]

13. Tamura M, Aizawa R, Hori M, Ozaki H (2009) Progressive renal dysfunction and macrophage infiltration in interstitial fibrosis in an adenine-induced tubulointerstitial nephritis mouse model. Histochem Cell Biol 131: 483-490. [Crossref]

14. Morishita Y, Ohnishi A, Watanabe M, Ishibashi K, Kusano E (2011) Establishment of acute kidney injury mouse model by $0.75 \%$ adenine ingestion. Renal failure 33 : 1013-1018. [Crossref]

15. Jia T, Olauson H, Lindberg K, Amin R, Edvardsson K, et al. (2013) A novel model of adenine-induced tubulointerstitial nephropathy in mice. BMC Nephrol 14: 116. [Crossref]
16. Akchurin O, Sureshbabu A, Doty SB, Zhu YS, Patino E, et al. (2016) Lack of hepcidin ameliorates anemia and improves growth in an adenine-induced mouse model of chronic kidney disease. Am J Physiol Renal Physiol 311: F877-F889. [Crossref]

17. Bobeck EA, Meyer KM, Helvig C, Petkovich M, Cook ME (2012) Sevelamer Hydrochloride Binds Phosphate Released from Phytate in Chicks Fed 1alpha-Hydroxy Cholecalciferol. J Ren Nutr 23(1): 21-27.

18. Brezina B, Qunibi WY, Nolan CR (2004) Acid loading during treatment with sevelamer hydrochloride: mechanisms and clinical implications. Kidney Int Supplement: S39-S45.

19. Posner GH, Helvig C, Cuerrier D, Collop D, Kharebov A, et al. (2010) Vitamin D analogues targeting CYP24 in chronic kidney disease. J Steroid Biochem Mol Biol 121: 13-19. [Crossref]

20. Evan AP, Bledsoe SB, Connors BA, Deng L, Liang L, et al. (2001) Sequential analysis of kidney stone formation in the Aprt knockout mouse. Kidney Int 60: 910-923. [Crossref]

21. Hayashi S, Oe Y, Fushima T, Sato E, Sato H, et al. (2017) Protease-activated receptor 2 exacerbates adenine-induced renal tubulointerstitial injury in mice. Biochem Biophys Res Commun 483: 547-552

22. Helvig CF, Cuerrier D, Hosfield CM, Ireland B, Kharebov AZ, et al. (2010) Dysregulation of renal vitamin D metabolism in the uremic rat. Kidney Int 78: 463472. [Crossref]

23. Seiler S, Heine GH, Fliser D (2009) Clinical relevance of FGF-23 in chronic kidney disease. Kidney Int Suppl: S34-S42.

24. Hattenhauer O, Traebert M, Murer H, Biber J (1999) Regulation of small intestinal Na-P(i) type IIb cotransporter by dietary phosphate intake. Am J Physiol 277: G756762. [Crossref]

25. National Kidney Foundation (2003) K/DOQI clinical practice guidelines for bone metabolism and disease in chronic kidney disease. Am J Kidney Dis 42: S1-S201. [Crossref]

26. Cupisti A, D'Alessandro C, Valeri A, Capitanini A, Meola M, et al. (2010) Food intake and nutritional status in stable hemodialysis patients. Renal failure 32: 47-54. [Crossref]

27. Kestenbaum B, Sampson JN, Rudser KD, Patterson DJ, Seliger SL, et al. (2005) Serum phosphate levels and mortality risk among people with chronic kidney disease. $J \mathrm{Am}$ Soc Nephrol 16: 520-528. [Crossref]

28. Biehl RR, Baker DH (1997) Utilization of phytate and nonphytate phosphorus in chicks as affected by source and amount of vitamin D3. J Anim Sci 75: 2986-2993. [Crossref]

29. Snow JL, Baker DH, Parsons CM (2004) Phytase, citric acid, and 1 alphahydroxycholecalciferol improve phytate phosphorus utilization in chicks fed a cornsoybean meal diet. Poultry Sci 83: 1187-1192. [Crossref]

30. Birge SJ, Avioli RC (1981) Intestinal phosphate transport and alkaline phosphatase activity in the chick. Am J Physiol 240: E384-E390. [Crossref]

31. Moriuchi S, Deluca HF (1976) The effect of vitamin D3 metabolites on membrane proteins of chick duodenal brush borders. Arch Biochem Biophys 174: 367-372. [Crossref]

32. Norman AW, Mircheff AK, Adams TH, Spielvogel A (1970) Studies on the mechanism of action of calciferol. 3. Vitamin D-mediated increase of intestinal brush order alkaline phosphatase activity. Biochim Biophys Acta 215: 348-359.

33. Hirako M, Kamiya T, Misu N, Kobayashi Y, Adachi H, et al. (2005) Impaired gastric motility and its relationship to gastrointestinal symptoms in patients with chronic renal failure. J Gastroent 40: 1116-1122. [Crossref]

34. Nikolov IG, Joki N, Nguyen-Khoa T, Guerrera IC, Maizel J, et al. (2012) Lanthanum carbonate, like sevelamer-HCl, retards the progression of vascular calcification and atherosclerosis in uremic apolipoprotein E-deficient mice. Nephrol dial transplant 27: 505-513. [Crossref]

35. Cozzolino M, Staniforth ME, Liapis H, Finch J, Burke SK, et al. (2003) Sevelamer hydrochloride attenuates kidney and cardiovascular calcifications in long-term experimental uremia. Kidney Int 64: 1653-1661. [Crossref]

36. Rehm WS, White AS, Sanders SS, Feagin FF (1970) Adenine compounds on changes in optical density and motility of frog gastric mucosa. Am J Physiol 218: 1010-1014. [Crossref]

37. Sprague SM (2007) A comparative review of the efficacy and safety of established phosphate binders: calcium, sevelamer, and lanthanum carbonate. Curr Med Res Opin 23: 3167-3175. [Crossref]

Copyright: (C)2017 Bobeck EA. This is an open-access article distributed under the terms of the Creative Commons Attribution License, which permits unrestricted use, distribution, and reproduction in any medium, provided the original author and source are credited. 